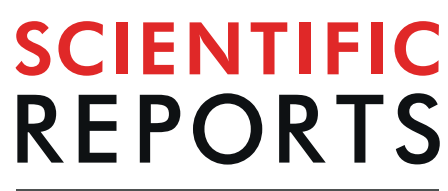

\title{
OPEN A class I cytosolic HSP20 of rice enhances heat and salt tolerance in different organisms
}

\author{
Liu-Ming Guo ${ }^{1,2,3}$, Jing $\mathrm{Li}^{1,3}$, Jing $\mathrm{He}^{1,2}$, Han $\mathrm{Liu}^{1,2}$ \& Heng-Mu Zhang ${ }^{1,2^{*}}$
}

Small heat shock proteins (sHSPs) have been thought to function as chaperones, protecting their targets from denaturation and aggregation when organisms are subjected to various biotic and abiotic stresses. We previously reported an sHSP from Oryza sativa (OsHSP20) that homodimerizes and forms granules within the cytoplasm but its function was unclear. We now show that OsHSP20 transcripts were significantly up-regulated by heat shock and high salinity but not by drought. A recombinant protein was purified and shown to inhibit the thermal aggregation of the mitochondrial malate dehydrogenase (MDH) enzyme in vitro, and this molecular chaperone activity suggested that OsHSP20 might be involved in stress resistance. Heterologous expression of OsHSP20 in Escherichia coli or Pichia pastoris cells enhanced heat and salt stress tolerance when compared with the control cultures. Transgenic rice plants constitutively overexpressing OsHSP2O and exposed to heat and salt treatments had longer roots and higher germination rates than those of control plants. A series of assays using its truncated mutants showed that its $\mathrm{N}$-terminal arm plus the $\mathrm{ACD}$ domain was crucial for its homodimerization, molecular chaperone activity in vitro, and stress tolerance in vivo. The results supported the viewpoint that OsHSP20 could confer heat and salt tolerance by its molecular chaperone activity in different organisms and also provided a more thorough characterization of HSP20-mediated stress tolerance in $O$. sativa.

Heat shock proteins (HSPs) have been thought to function as molecular chaperones, which are ubiquitous and evolutionarily conserved in both animals and plants and protect their target proteins from denaturation, misfolding and aggregation when subjected to various stresses in organisms ${ }^{1-7}$. HSPs can be classified by molecular weight and sequence similarity into at least five categories, namely HSPp100/ClpB, $90 \mathrm{kDa} H S P s, 70 \mathrm{kDa} H S P s$ (HSP70/DnaK), $60 \mathrm{kDa}$ chaperonins (HSP60/GroEL), and sHSPs of $15-42 \mathrm{kDa}^{8,9}$, in which sHSPS are the most abundant and diverse and play important roles in stress tolerance in plants ${ }^{10-12}$. The sHSP family can be further divided into several subfamilies, which target into the cytosol, nucleus, mitochondria, chloroplasts, or peroxisomes in plant cells $3,8,9,13-16$. Such a diversity of plant sHSPs reflect a molecular adaptation to various biotic and abiotic stress conditions. All members of sHSP family are characterized by the presence of a highly conserved alpha-crystallin domain (ACD), which comprises 80-100 amino acid residues and has been thought to function as a central structure element for oligomer $(200-800 \mathrm{kDa})$ formation in native state ${ }^{9,17-20}$. At the upstream of $\mathrm{ACD}$, the $\mathrm{N}$-terminal region appears to be quite flexible among sHSPs and has been thought to be involved in substrate binding and oligomer stability ${ }^{21-25}$.

Under biotic and abiotic stress conditions, a wide range of plant sHSPs have been revealed to act as molecular chaperones in vitro and in vivo independent of ATP, preventing protein denaturation or aggregation ${ }^{9,25-28}$. In the past decades, the expression of some plant sHSPs are shown to be triggered by heat ${ }^{29-31}$, salt ${ }^{32}$, drought ${ }^{33}$, osmosis $^{34}$, hormones ${ }^{35}$, heavy metal and oxidative stresses ${ }^{36-39}$, or plant developmental signals ${ }^{40,41}$. More evidences have suggested that certain plant sHSPs could enhance the stress tolerance when overexpressing in transgenic plants ${ }^{42-48}$. Despite the identification of diverse functions for various sHSPs in plants, the important roles undoubtedly played by many of these proteins remain to be discovered.

Rice (Oryza sativa), an excellent monocot model, is a unique crop feeding nearly half of the population in the world. During its lifecycle, the monocot plant typically has to cope with various stresses, which may greatly reduce rice yield and grain quality. Thus, it should be important to get deep insight into the mechanisms of

${ }^{1}$ Institute of Virology and Biotechnology, Zhejiang Academy of Agricultural Sciences, Hangzhou, 310021, China. ${ }^{2}$ College of Chemistry and Life Science, Zhejiang Normal University, Jinhua, 321004, China. ${ }^{3}$ These authors contributed equally: Liu-Ming Guo and Jing Li. *email: zhhengmu@tsinghua.org.cn 
(A)

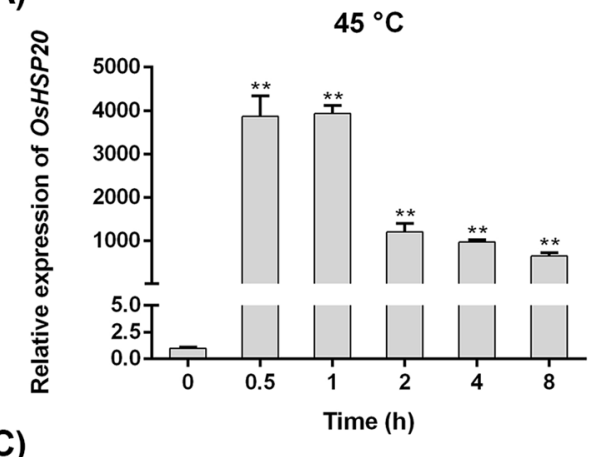

(C)

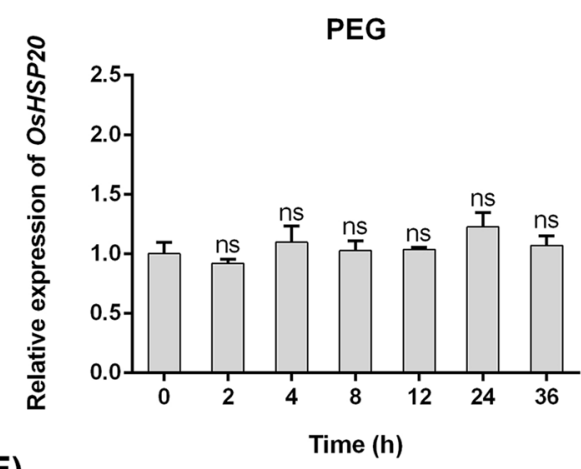

(E)

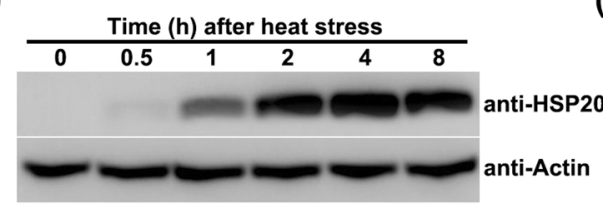

(B)

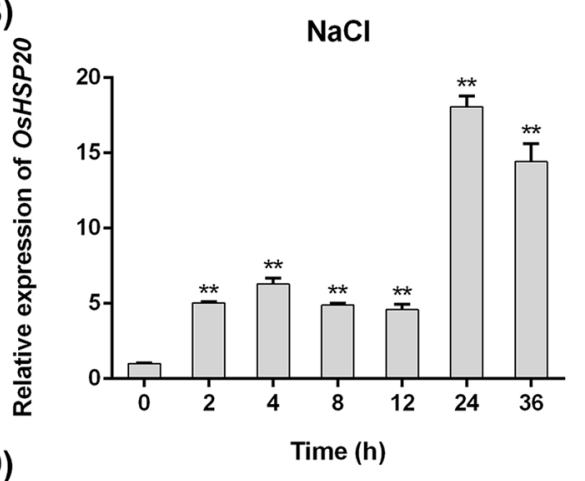

(D)

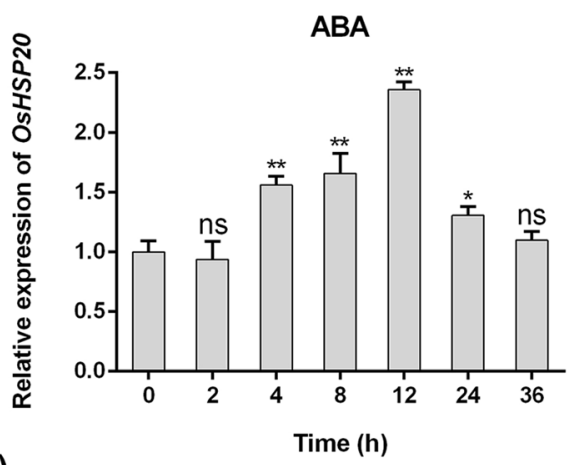

$(\mathrm{F})$

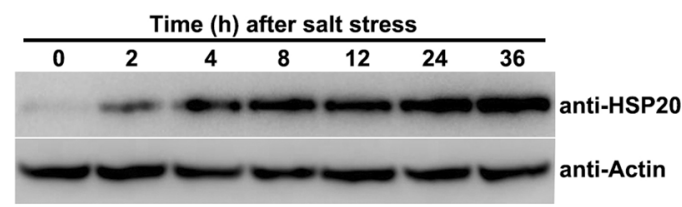

Figure 1. The expression of OsHSP20 in rice seedlings following various stresses: temperature of $45^{\circ} \mathrm{C}$ (heat stress) (A), $100 \mathrm{mM} \mathrm{NaCl}$ (salinity stress) (B), 5\% PEG (drought stress) (C), or $100 \mu \mathrm{M} \mathrm{ABA}$ (hormone stress) (D) analyzed by qRT-PCR (A-D) and Western blotting (E,F), in which the exposure time is $20 \mathrm{~s}$ or $150 \mathrm{~s}$ for detection of HSP20 protein under heat or salt stress, respectively. Data are mean \pm SD from three independent experiments. The asterisks on the top of the columns indicate significant differences from the value at $0 \mathrm{~h}(\mathrm{~ns}$, not significant; $* P<0.05 ; * * P<0.01)$.

stress resistance or tolerance in rice. We have previously isolated OsHSP20, a class I cytosolic sHSP from rice (Os03G026700), that interacts with a viral RNA dependent RNA polymerase (RdRp), homodimerizes and also forms granules within the cytoplasm ${ }^{49}$. However, its functions remain unclear. Here we reported the expression pattern of OsHSP20 under various abiotic stresses, its molecular chaperone activity in vitro and its role in stress tolerance when overexpressed in E. coli (a prokaryote), yeast and rice (eukaryotes). The key domains in the protein crucial for its homodimerization, molecular chaperone activity in vitro, and stress tolerance were further determined using a series of truncated mutants.

\section{Results}

OsHSP20 was significantly induced by both heat and salt stresses. The expression patterns of genes are known to be closely related to their functions and thus could provide a useful clue for exploration of gene function. To reveal the function of OsHSP20, its responses to various abiotic stresses, such as heat, salt, drought, and exogenous ABA treatments, were investigated by qRT-PCR. The transcription of OsHSP2O responded very quickly to heat stress, peaking at approximately 4,000-fold more transcripts than the control within $1 \mathrm{~h}$ and then decreasing, although levels were still much higher than the control at $8 \mathrm{~h}$ (Fig. 1A). Under salt stress, OsHSP2O mRNAs were significantly more abundant in the leaves of stressed plants compared to the controls at 2, 4, 8 and $12 \mathrm{~h}$ and peaked with values $14-18$ fold higher at $24-36 \mathrm{~h}$ (Fig. 1B). By contrast, over a $36 \mathrm{~h}$ period, the expression of OsHSP20 showed little or no change (less than 2.3-fold) in response to drought or exogenous ABA treatments (Fig. 1C,D). In Western blotting assays, the OsHSP20 protein was also found to accumulate to much higher level after heat and salt treatments (Fig. 1E,F and Supplementary Figs. S5 and S6).

Purified recombinant OsHSP20 acts as a molecular chaperone in vitro. Some sHSPs have been thought to function as molecular chaperones ${ }^{16,17}$. In order to determine the biochemical characteristics of OsHSP20, a prokaryotic expression vector harboring the full-length coding region of OsHSP20 (pET32a-OsHSP$20^{\text {Full }}$ ) was constructed and expressed in E. coli. The expression of recombinant OsHSP20 was induced and 
(A)

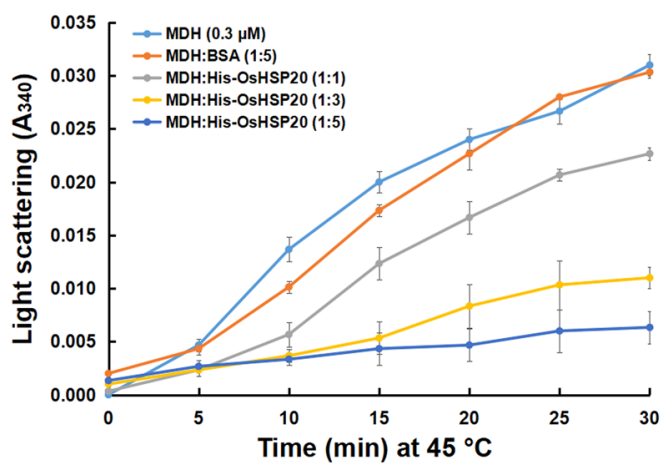

(B)

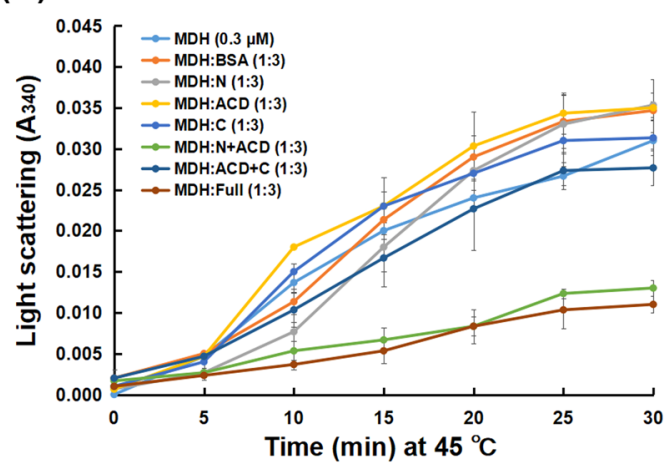

Figure 2. Chaperone activity assay of recombinant full-length (A) and truncated (B) OsHSP20 proteins. Chaperone activity was measured as the ability to prevent $\mathrm{MDH}$ denaturation under thermal-denaturing conditions at $45^{\circ} \mathrm{C}$. BSA was used as negative control. Data are the average of three independent experiments and shown as the mean \pm SD $(P<0.05)$. (A) $\mathrm{MDH}(0.3 \mu \mathrm{M})$ was incubated in the absence or presence of purified recombinant His-OsHSP20 protein, in which various molar ratios of MDH to His-OsHSP20 (1:1, 1:3 or 1:5) were examined. (B) $\mathrm{MDH}(0.3 \mu \mathrm{M})$ was incubated in the absence or presence of truncated OsHSP20 proteins (N, His-OsHSP20N; ACD, His-OsHSP20ACD; C, His-OsHSP20C; N + ACD, His-OsHSP20N + ACD; $\mathrm{ACD}+\mathrm{C}$, His-OsHSP20ACD $+\mathrm{C}$ ) with a molar ratio 1:3 of $\mathrm{MDH}$ to recombinant protein, in which purified recombinant His-OsHSP20 protein (Full) was used as positive control.

validated by SDS-PAGE and western blot assays (Supplementary Fig. S1A,B). The recombinant protein was purified with nickel-sulfate-coupled affinity column and its effect on the aggregation rate of $\mathrm{MDH}$ at $45^{\circ} \mathrm{C}$ was measured. It was clear that the recombinant OsHSP20 protein markedly inhibited the aggregation of $\mathrm{MDH}$ at high temperature (Fig. 2A). It was also notable that different concentration of OsHSP20 had the various effects on the heat-triggered aggregation rate of $\mathrm{MDH}$ and the maximum effect (over $80 \%$ ) was achieved when a molar ratio of MDH to OsHSP20 was equal to 1:5 (Fig. 2A), reflecting the protection in a dose-dependent manner. In contrast, BSA (bovine serum albumin; negative control) at a 1:5 M ratio (MDH:BSA) did not protect $\mathrm{MDH}$ from aggregation. This in vitro activity suggests that OsHSP20 may function as a molecular chaperonin in vivo.

OsHSP20 enhanced the viability of $E$. coli and yeast cells under thermal and salt stress. Since above experiments had shown that recombinant OsHSP20 was effectively expressed in E. coli BL21(DE3) pLysS transformed with the pET32a-OsHSP20, this overexpression system was used for cell viability assays to investigate the possible functions of OsHSP20 in vivo. Under normal conditions, the growth curve of E. coli cells with the pET32a-OsHSP20 plasmid appeared to be very similar to that of control cells (data not shown). To investigate the effect of heat stress on survival of recombinant $E$. coli cells, the cultures were subjected to $50^{\circ} \mathrm{C}$ for $1-3 \mathrm{~h}$ and then shifted to $37^{\circ} \mathrm{C}$ for recovery. Cell viability decreased in all cultures subjected to heat shock $\left(50^{\circ} \mathrm{C}\right)$ for $1-3 \mathrm{~h}$, but cells expressing full-length OsHSP20 always survived better than those harboring the empty pET32a $(+)$ vector (Fig. 3A). For example, after a $1 \mathrm{~h}$ heat shock approximately $30 \%$ of control cells survived compared with $85 \%$ of those expressing full-length OsHSP20. The corresponding figures after a $3 \mathrm{~h}$ heat shock were respectively $20 \%$ compared to nearly 50\% (Fig. 3A and Supplementary Fig. S2A). For salt stress tolerance assays, aliquots from IPTG-induced cultures were treated with $\mathrm{NaCl}$ and then plated on $\mathrm{LB}$ medium. As shown in Fig. 3B, cells expressing the full-length OsHSP20 survived better than the controls at all time-points: after $3 \mathrm{~h}$ treatment, over $50 \%$ of cells expressing full-length OsHSP20 had survived whereas no more than $20 \%$ of control cells had done so (Fig. 3B and Supplementary Fig. S2B). Thus, OsHSP20, a molecular chaperonin, confers thermal and salt tolerance to a representative prokaryote.

To determine the behavior of OsHSP20 as a molecular chaperonin in eukaryotic cells, the coding region of OsHSP20 was sub-cloned into pPIC3.5 K expression vector (designed as pPIC3.5K-OsHSP20 Full) and transformed into $P$. pastoris, a model yeast cell. The yeast cells transformed with empty pPIC3.5 K vector were used as the control. The effective expression of recombinant OsHSP20 protein in the P. pastoris cells was validated by Western blot assays with an anti-HSP20 antibody (Supplementary Fig. S3). Similar viability was observed for test and control recombinant $P$. pastoris cells under normal conditions (Fig. 3C). To evaluate the effect of high temperature on the viability of recombinant Pichia cells, 10 -fold serial dilutions of cultures were spotted on the YEPD medium plate and then incubated at $50^{\circ} \mathrm{C}$ for $1 \mathrm{~h}$ before shifted to $30^{\circ} \mathrm{C}$ for $2-3 \mathrm{~d}$. It was notable that the yeast cells expressing full-length OsHSP20 grew better than those harboring the pPIC3.5 K vector alone (Fig. 3D). Similarly, the growth of Pichia cells expressing full-length OsHSP20 was better than the controls under salt stress (Fig. 3E). It was concluded, therefore, that OsHSP20 also enhances the tolerance to thermal and salt stresses of a eukaryotic unicellular organism.

The domains required for OsHSP20 homodimerization. We previously reported that the OsHSP20 protein homodimerizes and forms granules within the cytoplasm ${ }^{49}$. To further determine the key domains of OsHSP20 responsible for homodimerization, we amplified and constructed five truncated mutants of OsHSP20 expressing either the N-terminal region $(\mathrm{N})$, ACD domain, C-terminal region $(\mathrm{C}), \mathrm{N}+\mathrm{ACD}$ or 
(A)

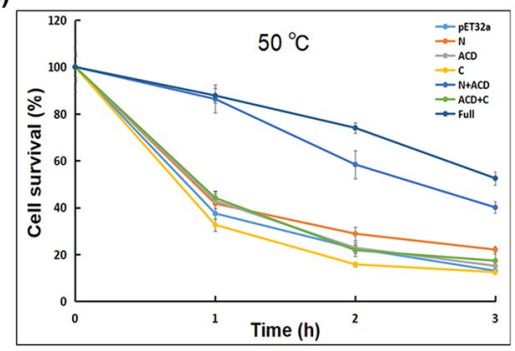

(B)

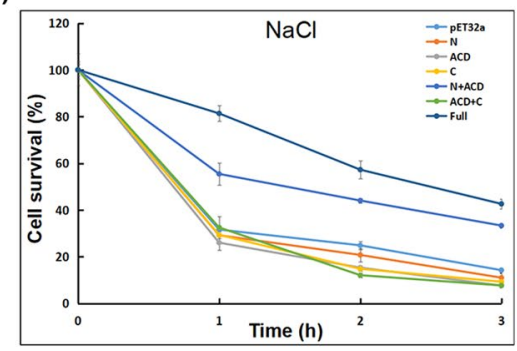

(C)

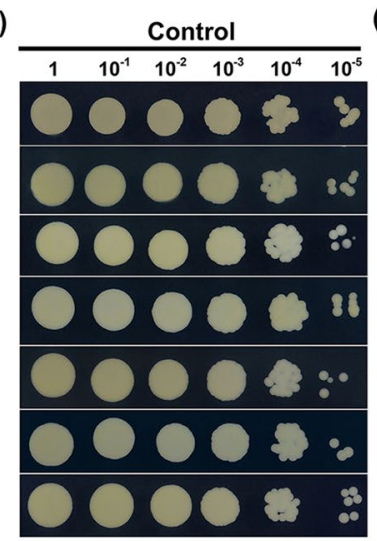

(D)

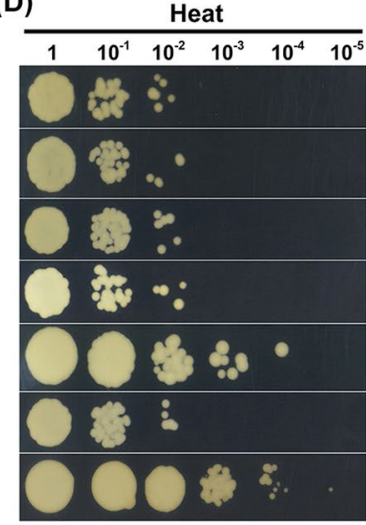

(E)

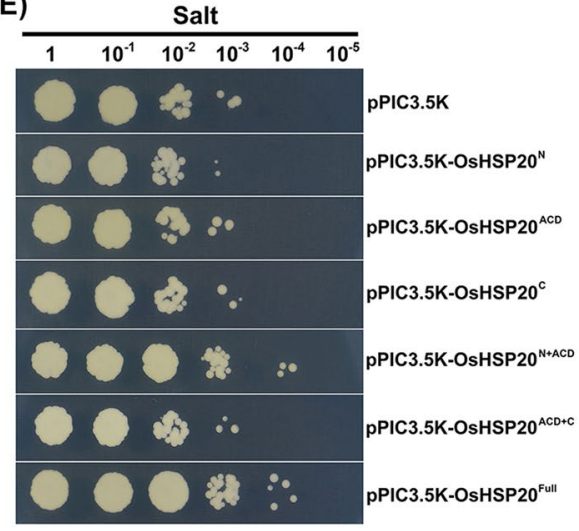

Figure 3. The effects of OsHSP20 overexpression on the growth of E. coli BL21 (A,B) and P. pastoris strain SMD1168 (C-E) under thermal and salt stress conditions. (A,B) Cell survival of $E$. coli expressing pET32a $(+)$ and transformants $\left(\mathrm{N}\right.$, pET32a-OsHSP20 $0^{\mathrm{N}}$; ACD, pET32a-OsHSP20 ${ }^{\mathrm{ACD}}$; C, pET32a-OsHSP20 $; \mathrm{N}+\mathrm{ACD}$, pET32a-OsHSP20 $0^{\mathrm{N}+\mathrm{ACD}}$; ACD $+\mathrm{C}$, pET32a-OsHSP20 ${ }^{\mathrm{ACD}+\mathrm{C}}$; Full, pET32a-OsHSP20 ${ }^{\text {Full }}$ ) grown after exposure to high temperature $\left(50^{\circ} \mathrm{C}\right)(\mathbf{A})$ or $800 \mathrm{mM} \mathrm{NaCl}(\mathbf{B})$ for different times $(X$-axis) before shifting to normal conditions for recovery. The data are the average of three independent experiments and shown as the mean $\pm \mathrm{SD}(P<0.05)$. (C-E) The SMD1168 strain was transformed with pPIC3.5 K (empty vector), pPIC3.5K-OsHSP20 $0^{\mathrm{N}}$, pPIC3.5K-OsHSP20 ${ }^{\mathrm{ACD}}$, pPIC3.5K-OsHSP20 ${ }^{\mathrm{C}}$, pPIC3.5K-OsHSP20 $0^{\mathrm{N}+\mathrm{ACD}}$, pPIC3.5KOsHSP2 $0^{\mathrm{ACD}+\mathrm{C}}$ or pPIC3.5K-OsHSP20 $0^{\text {Full }}$. Serially diluted samples $(5 \mu \mathrm{l})$ were spotted onto plates of YEPD medium after heat $\left(50^{\circ} \mathrm{C}\right.$ for $\left.1 \mathrm{~h}\right)(\mathbf{D})$ and salt $(1.2 \mathrm{M} \mathrm{NaCl})(\mathbf{E})$ treatments. The untreated group incubated at $30^{\circ} \mathrm{C}$ was used as a control (C). Colonies were photographed 3 days after inoculation.

$\mathrm{ACD}+\mathrm{C}$ (Fig. 4A). These truncated mutants were subcloned into the pGADT7 or pGBKT7 vectors and used for YTH assays. When the C-terminal extension region of OsHSP20 was removed (OsHSP20 $\left.{ }^{\mathrm{N}+\mathrm{ACD}}\right)$, there was no change in homodimerization. The yeast cells co-transformed with the plasmid pairs BD-OsHSP20 Full/ $\mathrm{AD}-\mathrm{OsHSP} 20^{\mathrm{N}+\mathrm{ACD}}$ and BD-OsHSP22 $0^{\mathrm{N}+\mathrm{ACD}} / \mathrm{AD}-\mathrm{OsHSP} 20^{\mathrm{N}+\mathrm{ACD}}$ appeared to grow well and turn blue (Fig. 4B), which were very similar to those of BD-OsHSP20 $0^{\text {Full }} / \mathrm{AD}-\mathrm{OsHSP} 20^{\mathrm{Full}}$ and the positive control BD-53/AD-T on $\mathrm{SD} /$-Ade/-His/-Leu/-Trp/X- $\alpha$-Gal/AbA medium (Fig. 4B). There was no visible growth of cells co-transformed with other plasmid combinations showing that the other truncated mutants were unable to homodimerize and therefore that the N-terminal arm plus the ACD domain were required for OsHSP20 dimerization.

OsHSP20 enhances tolerance to heat and salt stresses in transgenic rice plants. To investigate the function of OsHSP20 in vivo in rice plants, the full-length coding region of OsHSP20 was constructed into a binary vector ( $\mathrm{p} 1300$-OsHSP20) under the control of the ubiquitin promoter and transformed into rice, generating transgenic plants constitutively overexpressing OsHSP20. Three independent T2 transgenic rice lines (Ubi:OsHSP20-L5, -L16 and -L20) were selected for functional analysis after western blot and qRT-PCR assays showed that both transcripts and proteins of OsHSP20 were accumulated up to higher levels in all of them (Supplementary Figs. S4 and S7). To identify their thermotolerance, the sterilized seeds of three T2 generation transgenic rice lines and the wild-type (WT) control were treated at $50^{\circ} \mathrm{C}$ for $12 \mathrm{~h}$ on $1 / 2 \mathrm{MS}$ medium and then shifted to normal growth condition $\left(25^{\circ} \mathrm{C}\right)$ for calculation of their survival rates. When incubated under normal growth conditions $\left(25^{\circ} \mathrm{C}\right)$, both transgenic and WT seeds had almost $90 \%$ germinate rates within 10 days (Fig. 5A,C). However, following heat stress $\left(50^{\circ} \mathrm{C}\right.$ for $\left.12 \mathrm{~h}\right)$, no more than $10 \%$ of the WT seeds had germinated compared to $67-83 \%$ in the transgenic lines expressing OsHSP20 (Fig. 5A,D). Thus, OsHSP20 improved the germination of seeds subjected to thermal stress. The primary root lengths of those seedlings that grew were also compared. Under normal growth conditions $\left(25^{\circ} \mathrm{C}\right)$, the OsHSP20 transgenic and WT plants had similar root lengths but growth was inhibited by the heat treatment and the effect was much more severe in the WT than in the transgenic rice plants (Fig. 5B,E). To investigate the effect of heat stress on aerial parts, the transgenic and WT seedlings grew at 25 or $38^{\circ} \mathrm{C}$ and their plant height and leaf chlorophyll contents were also analyzed. They almost had similar height and chlorophyll contents when grown at $25^{\circ} \mathrm{C}$, however, the detrimental effect on aerial parts 
(A)

BD-

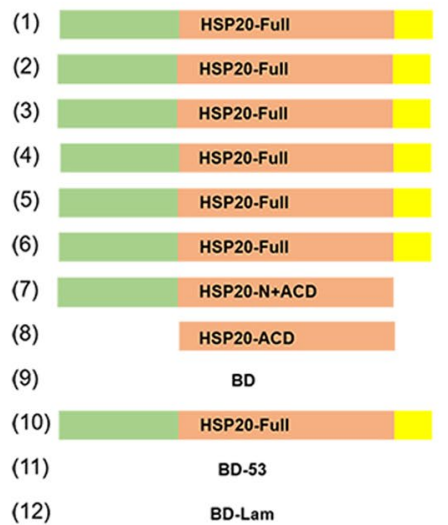

$X$

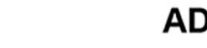

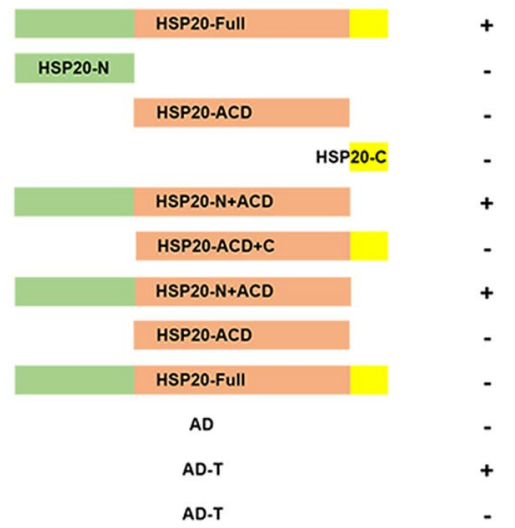

(B)

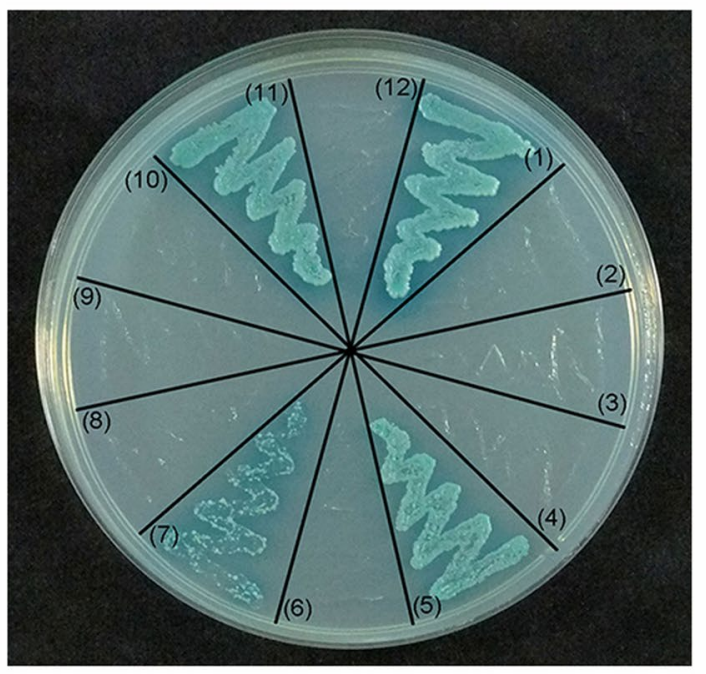

Figure 4. Investigation of OsHSP20 homodimerization in yeast cells. (A) Schematic representation of OsHSP20 and the five truncations generated in the study. The full-length OsHSP20 (Full; spanning residues 1 to 158) was divided into three parts: the $\mathrm{N}$-terminal arm (N; spanning residues 1 to 52 ), the $\alpha$-crystallin domain (ACD; residues 52 to 143) and the $\mathrm{C}$-terminal extension region (C; residues 143 to 158). Five truncated forms of OsHSP20 were prepared to express N, ACD , C, N + ACD or ACD + C. The presence $(+)$ or absence $(-)$ of homodimerization in YTH assay is shown on the right. (B) Interaction of intact OsHSP20 and truncations of OsHSP20 in co-transformed yeast cells grown on SD/-Ade/-His/-Leu/-Trp/X- $\alpha-G a l / A b A$ medium. Yeast colonies expressing BD-53/AD-T were used as the positive control. Yeast co-transformed with BD-Lam/AD-T, $\mathrm{BD}-\mathrm{OsHSP} 20^{\text {Full }} / \mathrm{AD}$ or BD/AD-OsHSP20 $0^{\text {Full }}$ were used as negative controls.

also appeared to be more severe in the WT than in the transgenic seedling when grown at $38^{\circ} \mathrm{C}$ (Fig. $\left.5 \mathrm{~F}-\mathrm{H}\right)$. The results therefore show that transgenic overexpression of OsHSP20 increased thermotolerance in rice during germination and growth development.

To investigate the roles of OsHSP20 in defense to salt stress, the germination rate and root elongation was quantified. Under normal growth conditions, the germination rate and root lengths of the transgenic seedlings appeared to be no significantly different from those of WT (Fig. 6). Under salt stress, root growth of WT plants was obviously inhibited $(3.2 \mathrm{~cm})$ but this inhibition was significantly alleviated (lengths of $5.5-6.1 \mathrm{~cm})$ by transgenic overexpression of OsHSP20 (Fig. 6A,B). All transgenic lines germinated significantly more than WT under salt stress although treatment with $100 \mathrm{mM} \mathrm{NaCl}$ appeared to have mild effect on germination rate (Fig. 6C). Thus, when OsHSP20 was overexpressed it functioned as a molecular chaperonin, conferring heat and salt tolerance to rice.

The domains required for the chaperone and stress tolerance activity of OsHSP20. To investigate the domains of OsHSP20 required for chaperone activity, the truncated mutants described above were individually constructed into plasmid $\mathrm{pET} 32 \mathrm{a}(+)$, a prokaryotic expression vector, and then transformed respectively into E. coli for recombinant expression. The purified truncated proteins were then tested for their ability to protect $\mathrm{MDH}$ against thermal-induced denaturation. As expected, the full-length protein of OsHSP20 displayed 
(A)

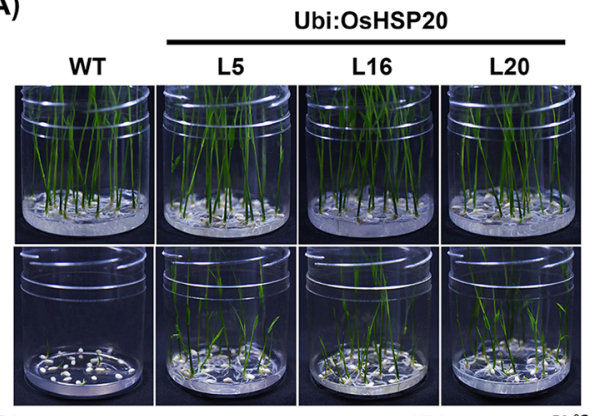

(C)

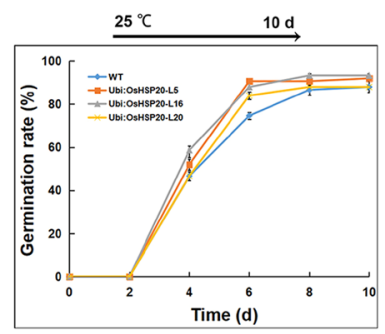

(F)

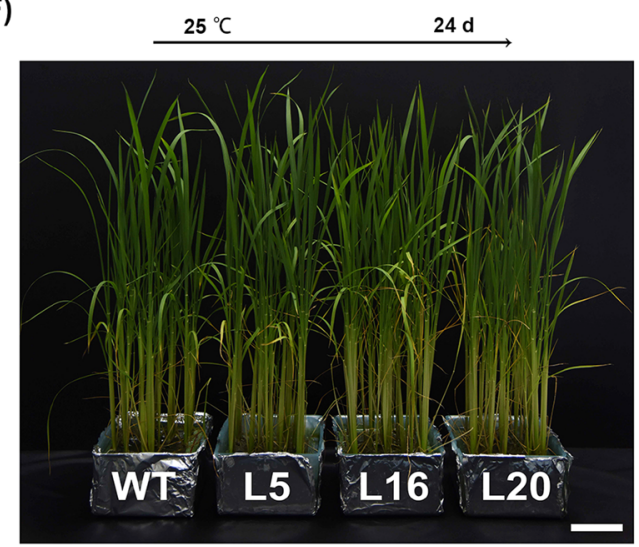

(G)

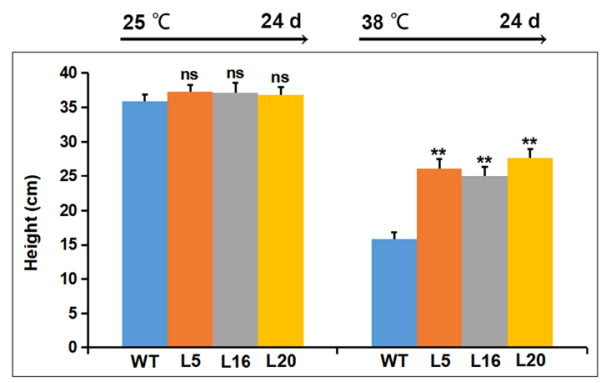

(B)

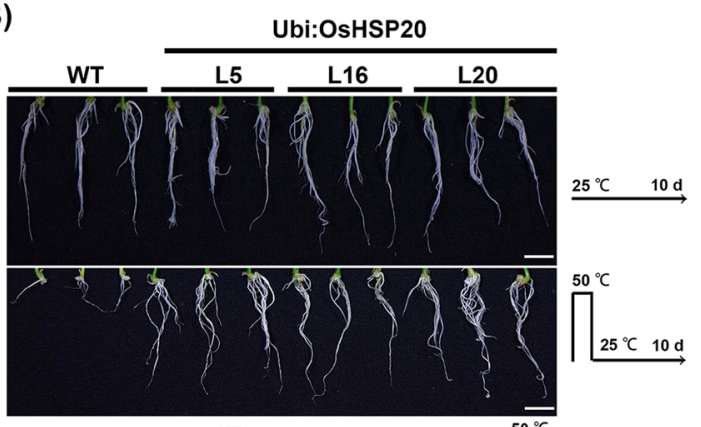

(E)
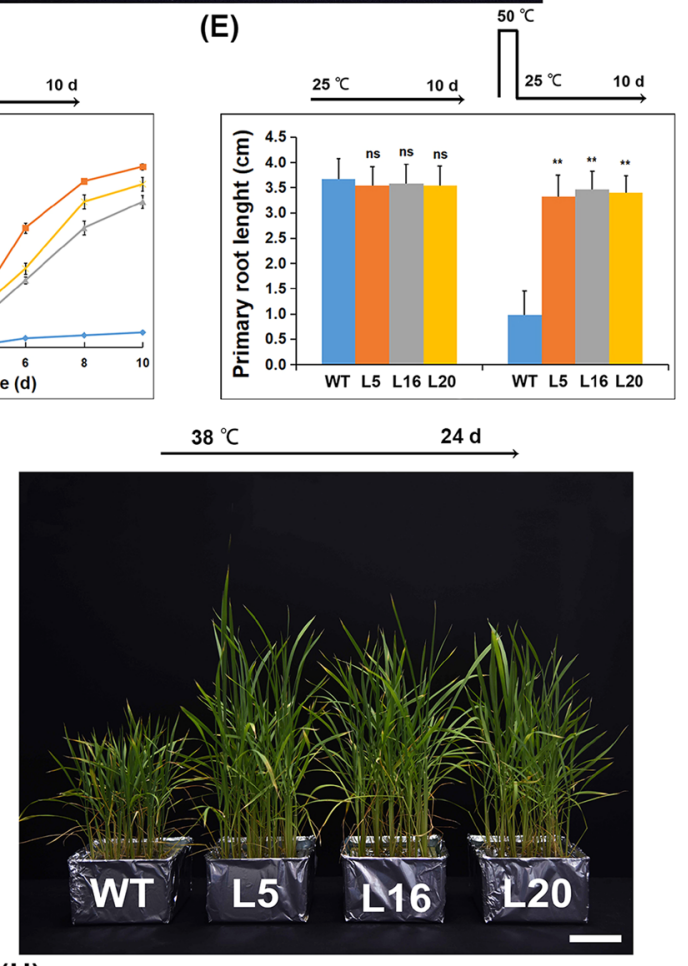

(H)

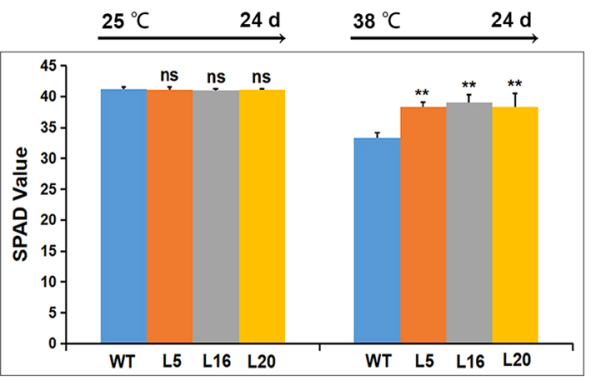

Figure 5. Comparison of seed germination rates (A,C,D), root lengths (B,E), plant height $(\mathbf{F}, \mathbf{G})$, and leaf chlorophyll contents $\mathbf{( H )}$ from WT and transgenic OsHSP20 rice plants under heat stress. (A) Germination rates of untransformed wild-type (WT) and lines overexpressing OsHSP20 (Ubi:OsHSP20-L5, -L16 and -L20) under thermal treatment $\left(50^{\circ} \mathrm{C}\right)$ for $12 \mathrm{~h}$. Photographs were taken after 10 days of recovery at $25^{\circ} \mathrm{C}$. (B) Root length phenotype of 10-day-old untransformed wild-type (WT) and lines overexpressing OsHSP20 (Ubi:OsHSP20-L5, -L16 and -L20). Imbibed seeds were treated at $50^{\circ} \mathrm{C}$ for $12 \mathrm{~h}$, and photographs were taken after 10 days of recovery at $25^{\circ} \mathrm{C}$. Scale bar is $1 \mathrm{~cm}$. (C,D) show time course of germination (in days after imbibition) for freshly harvested seeds of WT and the overexpression lines. Seeds were surface-sterilized and plated on 1/2 MS medium under normal growth conditions $\left(25^{\circ} \mathrm{C}\right)(\mathbf{C})$ or were first incubated at $50^{\circ} \mathrm{C}$ for $12 \mathrm{~h}$ and then moved to a growth chamber set at $25^{\circ} \mathrm{C}(\mathbf{D})$. Germination rate was measured at $2 \mathrm{~d}$ intervals after shifting to $25^{\circ} \mathrm{C}$. Data represent the mean $\pm \mathrm{SD}(P<0.05)$ from three independent experiments. (E) Quantitative analysis of primary root lengths of 10-day-old seedlings from WT and each transgenic line. The average $( \pm S D)$ values are from three biological replicates with 30 plants for each line and replicate. Significant differences between WT and transgenic plants are indicated by asterisks (ns, not significant; $* * P<0.01)$. (F) Phenotype of transgenic and WT plants grew at $25^{\circ} \mathrm{C}$ for 24 days (Left) and $38^{\circ} \mathrm{C}$ for 24 days (Right). (G) Quantitative analysis of plant height from WT and each transgenic line grew at 25 or $38^{\circ} \mathrm{C}$ for 24 days. (H) Quantitative analysis of leaf chlorophyll contents from WT and transgenic lines grew at 25 or $38^{\circ} \mathrm{C}$ for 24 days. 
(A) Ubi:OsHSP20

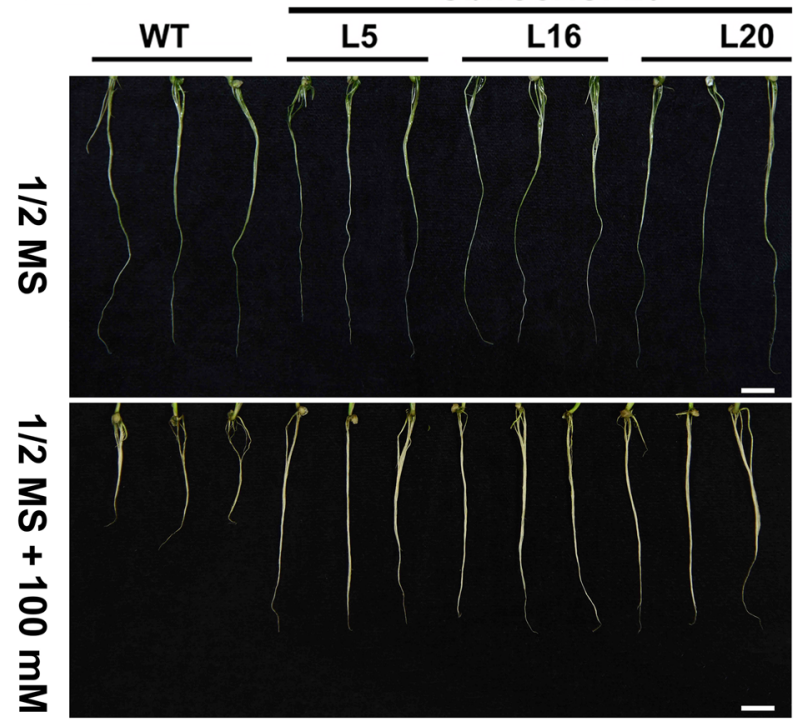

(B)

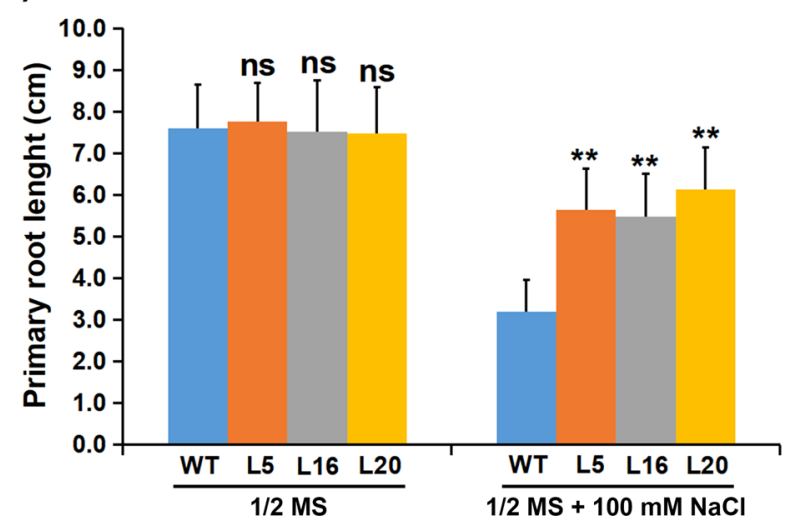

(C)

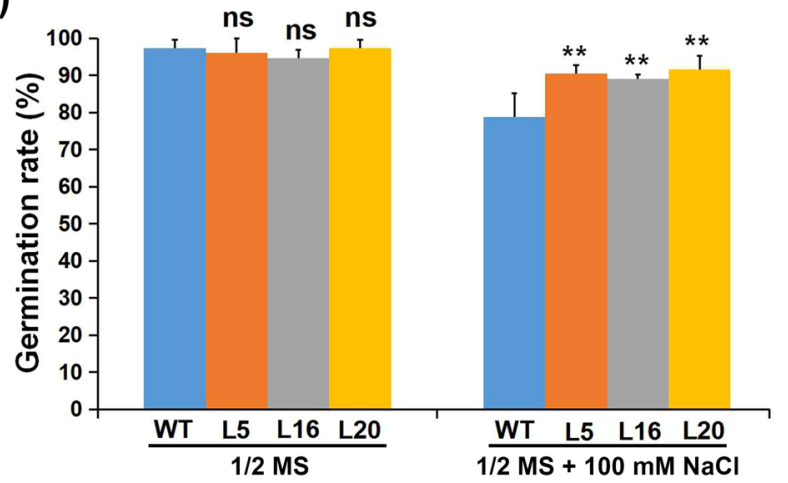

Figure 6. Comparison of root lengths $(\mathbf{A}, \mathbf{B})$ and seed germination rates $(\mathbf{C})$ of transgenic OsHSP20 rice plants under salt stress. (A) Root length phenotype of 2-week-old untransformed wild-type (WT) and OsHSP20 overexpression lines (Ubi:OsHSP20-L5, -L16 and -L20). WT and transgenic plants were germinated on 1/2 MS medium plates for 3 days before transfer to a new MS medium plate supplemented with $100 \mathrm{mM} \mathrm{NaCl}$ for 2 weeks. Scale bar is $1 \mathrm{~cm}$. (B) Quantitative analysis of primary root lengths of 2-week-old seedlings from WT and each transgenic line. The average $( \pm S D)$ values are from three biological replicates with 50 plants for each line and replicate. Significant differences between WT and transgenic plants are indicated by asterisks (ns, not significant; $* * P<0.01$ ). (C) Germination rates were measured at $6 \mathrm{~d}$ after incubating seeds at $25^{\circ} \mathrm{C}$ with or without salt stress. Data represent the mean $\pm \mathrm{SD}(\mathrm{P}<0.05)$ from three independent experiments. 
strongest chaperone activity, effectively protecting $\mathrm{MDH}$ from thermal-induced aggregation. The $\mathrm{N}+\mathrm{ACD}$ mutant protein had similar activity to that of the full-length OsHSP20 but none of the other mutant proteins inhibited MDH denaturation (Fig. 2B).

The same truncated mutant constructs were also sub-cloned into pET32a $(+)$ or pPIC3.5 K vectors and transformed into E. coli or P. pastoris cells, respectively for tests of thermal and salt stress tolerance as described above. In both E. coli (Fig. 2B and Supplementary Fig. S2) and P. pastoris (Fig. 2D,E and Supplementary Fig. S3) the cells with full-length OsHSP20 and those with the N + ACD mutant survived equally well but there was no evidence of stress tolerance in cells harboring the constructs of $\mathrm{N}, \mathrm{ACD}, \mathrm{C}$, or ACD $+\mathrm{C}$. Taken together, the results suggested that the N-terminal arm plus the ACD domain was necessary for the homodimerization of OsHSP20 and for its in vitro chaperone and stress tolerance activity.

\section{Discussion}

Plant sHSPs are thought to be molecular chaperones that prevent their target proteins or structures from stress-induced aggregation or denaturation, and thus maintain or recover the protein function for plant growth and development under various stresses ${ }^{3}$. Some of sHSP genes, such as RcHSP17.8 (a Rosa chinensis sHSP gene) ${ }^{44}$, ThHSP18.3 (a Tamarix hispida sHSP gene) ${ }^{50}$, and LimHSP16.45 (a David Lily sHSP gene) ${ }^{51}$, have been reported to be strongly regulated by various types of stresses, including heat, cold, salt, drought, osmotic or oxidative stress $^{47,48,52,53}$. In our experiments, the expression of OsHSP20 was strongly up-regulated by heat or salt stress but a little or insignificantly affected by ABA treatments or drought stress (Fig. 1), suggesting that it might play different roles in response to the various stresses. The increased transcript abundance of OsHSP2O in response to heat stress reached a peak in the first hour (Fig. 1A), suggesting that the signal transduction response could be rapid and transient and that such expression pattern of OsHSP20 might be a kind of mechanism whereby plants rapidly adapt to heat stress. It was also noted that the accumulation of OsHSP20 protein were not always consistent with the transcriptional level of OsHSP20 although they had an increasing tendency under both heat and salt stresses (Fig. 1A,B,E,F). Such differences could be partly caused by the fact that translational process always lags behind the transcription in eukaryotes. The transcriptional level of OsHSP20 appeared to fluctuate greatly with treatment time, however, accumulation of OsHSP20 increased stably, especially in salt treatment, suggesting that its transcription could be regulated by a complexed mechanism in vivo and accumulation of stable OsHSP20 proteins might affect its transcription via feedback. By contrast, the signal transduction appeared to be obviously slower in response to salt stress than to heat shock, suggesting a different signal pathway. The endogenous phytohormone abscisic acid (ABA) are well-known to play important roles in response to various stresses ${ }^{54}$. In our experiments, the transcription of OsHSP20 was a little changed (2.3-fold) by treatment with ABA for $12 \mathrm{~h}$ (Fig. 1D), suggesting that OSHSP20 might be partially involved in the ABA-mediated pathway.

The introduction of plant genes into unicellular organisms is a simple and rapid method for exploration of their putative roles in vivo. By this method, some of sHSPs from a few species of plants have been characterized to be specifically involved in defense to certain types of stress tolerances, including E. coli expressing CpHSP40 from Cydia pomonella ${ }^{55}$, CsHSP17.5 from chestnut (Castanea sativa) ${ }^{43}$, or mitochondrial HSP23 from Medicago sativa ${ }^{56}$ and P. pastoris producing RcHSP17.8 from Rosa chinensis ${ }^{44}$ or ThHSP18.3 from Tamarix hispida ${ }^{50}$. In this work, we introduced the OsHSP20 coding sequence into both E. coli and P. pastoris and found that cells overexpressing OsHSP20 were protected to some degree against heat and salt stress. Plant sHSPs have been shown more similar to sHSPs from yeast, a model eukaryotic cell, than to sHSPs of $E$. coli, a prokaryotic cell ${ }^{57,58}$. The effects of OsHSP20 on stress tolerances could be much more balanced by homologous sHSP genes in yeast than in $E$. coli and thus, in this study, the protective effect of OsHSP20 seemed to be more efficient in E. coli than that in yeast.

In addition, the OsHSP20 gene was placed under the control of a Ubi promoter and transformed by Agrobacterium-mediated method into rice plants. Measurements of germination rates and root lengths of rice seedlings showed that the transgenic rice plants were more tolerant of both high temperature (Fig. 5) and salt stress (Fig. 6) than WT control plants. Similar results were also obtained when some sHSPs of several plant species, including PfHSP21.4 (Primula), ZmHSP16.9 (maize), PtHSP17.8 (Populus trichocarpa) and wheat sHSP26.8, were overexpressed in transgenic plants in response to stresses ${ }^{29,33,34,45,59-62}$. However, the detailed molecular mechanism that the OsHSP20 facilitated the germination and root elongation under high temperature and salt stresses remained to be clarified. These transgenic rice lines might provide an excellent plant material for future studies.

Molecular chaperones can bind their target proteins to prevent the denaturation or aggregation of proteins under adverse conditions ${ }^{3,63}$. LimHSP16.45 and another rice sHSP, OsHSP18.2, have been found to act as molecular chaperones to improve cell viability under stress ${ }^{51,64}$. Our results showed that OsHSP20 had the activity of molecular chaperone in vitro and enhanced the tolerance to heat and salt stresses, suggesting that the rice sHSP could renature the aggregated mitochondrial malate dehydrogenase $(\mathrm{MDH})$ in vitro and that it could protect its target proteins from denaturation induced by stresses in cells. Two other sHSP genes, AtHSP17.4 and CsHSP17.2, have been found to be more actively upregulated in transgenic plants under heat shock ${ }^{65,66}$. We also could not preclude a possibility that transgenic overexpression of OsHSP20 might induce sHSP synthesis and partially contributed to stress tolerances. Using truncated OsHSP20 mutants, we also showed that the homodimerization of the protein and its in vitro biochemical activity and in vivo stress tolerance effects all depended on its $\mathrm{N}$-terminal arm plus ACD domains (Figs. 2B and 3). This suggests that its biological activity depends upon its homodimerization. The N-terminal arms of TaHSP16.9, PsHSP18.1 and DgHSP17.2 all have been shown to be crucial for their molecular chaperone activity ${ }^{23,67}$, which is consistent with our results. These results support the view that the N-terminal arm may be essential for the biochemical characteristics of sHSPs, irrespective of subfamily ${ }^{23}$. The $\mathrm{N}$-terminal region has also been thought to be associated with the substrate or target specificity ${ }^{23}$. We therefore suggest that the $\mathrm{N}$-terminal region of OsHSP20 should be important for both its in vitro chaperone activity and its stress tolerance in vivo by involving homodimerization and interaction with substrates or targets. 


\section{Conclusion}

In summary, we have shown that OsHSP20 is induced by heat shock and high salinity stresses. OsHSP20 has molecular chaperone activities in vitro. Overexpression of OsHSP20 in E. coli, P. pastoris and transgenic rice plants demonstrated that it can enhance heat and salt stress tolerance. Furthermore, the N-terminal region of OsHSP20 was identified to be closely associated not only with its in vitro chaperone activity, but also with its in vivo stress tolerance.

\section{Materials and Methods}

Plant materials and abiotic stress treatments. Seedlings of Rice (Oryza sativa L. spp. japonica. cv. Nipponbare) were grown in a greenhouse at $28^{\circ} \mathrm{C}$ with $16 \mathrm{~h}$ light $/ 8 \mathrm{~h}$ dark cycle and $70 \%$ relative humidity (r.h.) for two weeks before treatment. For heat treatment, the seedlings were placed in an incubator at a high temperature $\left(45^{\circ} \mathrm{C}\right)$ or were grown at $28^{\circ} \mathrm{C}$ in a culture room as controls. For salinity treatment, the seedlings were watered with $100 \mathrm{mM} \mathrm{NaCl}$ or with $\mathrm{ddH}_{2} \mathrm{O}$ as a control. For drought treatment, the roots of seedlings were irrigated with 5\% PEG6000 or with $\mathrm{ddH}_{2} \mathrm{O}$ as a control. For the exogenous ABA treatment, the seedlings were sprayed with $100 \mu \mathrm{M}$ abscisic acid (ABA) or with $0.1 \%(\mathrm{v} / \mathrm{v})$ ethanol solution (in which the compound was dissolved) as a control. After different times under these stresses, leaf samples were collected, immediately frozen in liquid nitrogen and stored at $-80^{\circ} \mathrm{C}$ before RNA and protein extraction. Each treatment was represented by three biological replicates, and samples from five plants were collected for each replicate.

RNA extraction and qRT-PCR. Total RNA was extracted using Trizol reagent (Invitrogen, Carisbad, California, USA) according to the manufacturer's instructions. The total RNA was first treated with DNase I (TaKaRa Bio, Dalian, China) and then reverse transcribed to cDNA using ReverTra Ace (Toyobo Co., Osaka, Japan) with oligo(dT) primers. $1 \mu \mathrm{l}$ of 10 -fold dilution cDNA from each sample was used for the quantitative analysis with SYBR Green Realtime PCR Master Mix (Toyobo). Data were obtained using the 7900 Real-Time PCR System (Applied Biosystems). The OsHSP20 gene specific primers Os20RT-F (5'-AAGTTCCTCCGCAGGTTCC-3') and Os20RT-R (5'-GAGCACGCCGTTCTCCAT-3') were used in assays. The rice ubiquitin-conjugating enzyme E2 (UBCE2) gene (LOC_Os02g42314) was used as an internal control with the primers OsUBC-F (5'-CCGTTTGTAGAGCCATAATTGCA-3') and OsUBC-R ( $5^{\prime}$-AGGTTGCCTGAGTCACAGTTAAGTG- $\left.3^{\prime}\right)$. The reactions were incubated in a 384 -well plate at $95^{\circ} \mathrm{C}$ for $3 \mathrm{~min}$ and then subjected to $40 \mathrm{cycles}$ of $95^{\circ} \mathrm{C}$ for $15 \mathrm{~s}, 60^{\circ} \mathrm{C}$ for $20 \mathrm{~s}$, and $72^{\circ} \mathrm{C}$ for $30 \mathrm{~s}$. Each experiment was replicated three times. The relative expression levels were calculated using the $2^{-\Delta \Delta \mathrm{Ct}}$ method $^{68}$.

Protein-protein interaction assays by yeast two-hybrid (YTH) system. The yeast GAL4 binding domain vector pGBKT7 and activation domain vector pGADT7 were used for YTH assays (Clontech, Palo Alto, $\mathrm{CA}$ ). To construct plasmids for $\mathrm{YTH}$, the coding sequences of the intact OsHSP20 protein and its five truncated mutants OsHSP20 $0^{\mathrm{N}}$ (aa 1-59), OsHSP20 ${ }^{\mathrm{ACD}}$ (aa 49-145), OsHSP20 ${ }^{\mathrm{C}}$ (aa 102-158), OsHSP20 $0^{\mathrm{N}+\mathrm{ACD}}$ (aa 1-145) and OsHSP20 ${ }^{\mathrm{ACD}+\mathrm{C}}$ (aa 49-158) were amplified separately using primer pairs YOs20-NF/YOs20-CR, YOs20-NF/ YOs20-NR, YOs20-ACDF/YOs20-ACDR, YOs20-CF/YOs20-CR, YOs20-NF/YOs20-ACDR and YOs20-ACDF/ YOs20-CR (Supplementary Table 1), respectively. The products were then cloned into the pGBKT7 and pGADT7 vectors by NdeI/BamHI restriction digestion, creating the bait and prey plasmids, BD- and AD-OsHSP20 Full, OsHSP $20^{\mathrm{N}}$, -OsHSP20 $0^{\mathrm{ACD}}$, -OsHSP20 $0^{\mathrm{C}}$, -OsHSP $20^{\mathrm{N}+\mathrm{ACD}}$ and -OsHSP2 $20^{\mathrm{ACD}+\mathrm{C}}$, respectively.

Yeast transformation was carried out according to the commercial procedures (Matchmaker Gold Yeast Two-Hybrid System; Yeastmaker Yeast Transformation System 2, Clontech). Saccharomyces cerevisiae strain Y2HGold was co-transformed with bait and prey plasmids using the small-scale lithium acetate $\operatorname{method}^{69}$. Co-transformants were first plated on SD/-Ade/-His/-Leu/-Trp medium, and positive colonies were then tested for $\alpha$-galactosidase activity on SD/-Ade/-His/-Leu/-Trp/X- $\alpha-\mathrm{Gal} / \mathrm{AbA}$ medium. The co-transformants with $\mathrm{BD}-53 / \mathrm{AD}-\mathrm{T}$ and BD-Lam/AD-T were used as positive and negative controls, respectively. Each YTH assay was performed in at least three replicates.

Expression and purification of OsHSP20 from $E$. coli. The coding sequences of the full-length OsHSP20 protein and its truncated mutants OsHSP20 $0^{\mathrm{N}}$, OsHSP20 $20^{\mathrm{ACD}}$, OsHSP $20^{\mathrm{C}}, \mathrm{OsHSP} 20^{\mathrm{N}+\mathrm{ACD}}$ and OsHSP $20^{A C D}+C$ were amplified separately using primer pairs PEOs20-NF/PEOs20-CR, PEOs20-NF/PEOs20-NR, PEOs20-ACDF/PEOs20-ACDR, PEOs20-CF/PEOs20-CR, PEOs20-NF/PEOs20-ACDR and PEOs20-ACDF/ PEOsHSP20-CR (Supplementary Table 1), respectively. The fragments were subsequently ligated into the SacI/NotI site of the expression vector pET32a $(+)$ (Novagen, Merck, Darmstadt, Germany) and placed in phase with the coding sequence of $\mathrm{C}$-terminal fusion peptide $(6 \times \mathrm{His})$. The resulting recombinant plasmids pET32a-OsHSP20 $20^{\text {Full }}$,-OsHSP20 $0^{\mathrm{N}}$, -OsHSP20 $0^{\mathrm{ACD}},-\mathrm{OsHSP} 20^{\mathrm{C}},-\mathrm{OsHSP} 20^{\mathrm{N}+\mathrm{ACD}},-\mathrm{OsHSP} 20^{\mathrm{ACD}+\mathrm{C}}$ and the empty vector were respectively transformed into Escherichia coli BL21(DE3) pLysS cells.

For the expression assay of the recombinant protein, a single clone of transformed E. coli was inoculated and cultured at $37^{\circ} \mathrm{C}$ overnight in Luria-Bertani medium with ampicillin. The culture was later refreshed to $\mathrm{OD}_{600}$ of $\sim 0.5$ and then incubated in the presence or absence of isopropyl- $\beta$-D-thiogalactopyranoside (IPTG; $1 \mathrm{mM}$ ). The E. coli cells were harvested and homogenized for lysis. After centrifugation, the lysate was analyzed via sodium dodecyl sulfate polyacrylamide gel electrophoresis (SDS-PAGE) ${ }^{70}$ and coomassie brilliant blue staining.

His-tagged OsHSP20 (His-OsHSP20) and truncated variants were purified by methods of nickel-nitrilotriacetic acid (Ni-NTA, Peptron) resin and subsequent dialysis as described in commercial manual. Their purity was assessed by the Bradford method ${ }^{71}$ using the Bio-Rad protein assay reagent (Bio-Rad, Hercules, CA, USA) and then validated by coomassie brilliant blue staining of the SDS-PAGE gel and western blot analysis.

Western blot analysis. Western blotting assays were carried out as previously described ${ }^{49}$. Briefly, protein samples (each sample containing $20 \mu \mathrm{g}$ of protein) were denatured and separated by SDS-PAGE. The electrophoresed proteins were transferred by using a Bio-Rad Mini Protean III transblotting system (Bio-Rad, Hercules, 
CA, USA) onto nitrocellulose membranes (Millipore, Bedford, MA, USA). The membranes were blocked in TTBS (200 mM Tris, pH 7.0, 1.37 M NaCl, 1\% Tween 20, and 3\% BSA) for $1 \mathrm{~h}$ and then treated with an anti-His monoclonal antibody (1:2,000 dilution; Quanshijin, Beijing, China), an anti-Actin monoclonal antibody (1:2000 dilution; Abbkine, Wuhan, China), or an anti-HSP20 polyclonal antibody (1:2,000 dilution; prepared and stored in our $\mathrm{Lab})^{72}$ as the primary antibody and an anti-rabbit horseradish peroxidase-conjugated secondary antibody (1:5,000 dilution; Kangweishiji, Beijing, China).

Chaperone activity assays. The chaperone activity of the recombinant His-OsHSP20 and its truncated proteins were evaluated by measuring their ability to prevent the thermal aggregation of malate dehydrogenase $(\mathrm{MDH})\left(\mathrm{EC}\right.$ 1.1.1.37; Sigma) as described previously ${ }^{73}$. Briefly, $\mathrm{MDH}(0.3 \mu \mathrm{M})$ was incubated at $45^{\circ} \mathrm{C}$ in a buffer (40 mM HEPES, pH 7.5) alone or with OsHSP20 at a molar ratio of 1:1, 1:3 or 1:5. Absorbance was measured at $340 \mathrm{~nm}$ at $5 \mathrm{~min}$ intervals for $30 \mathrm{~min}$. For each assay of chaperone activity, BSA was used as the negative control to preclude nonspecific chaperone activity and three independent experiments were performed.

Survival assay for $E$. coli under abiotic stresses. $\quad$ E. coli cells were cultivated to the stage $\left(\mathrm{OD}_{600}=1.0\right)$ at $37^{\circ} \mathrm{C}$ in LB medium and then transferred into fresh LB medium with $100 \mathrm{mg} / \mathrm{mL}$ ampicillin and $1 \mathrm{mM}$ IPTG. After expression induced for $2 \mathrm{~h}$, the cultures were shifted to $50^{\circ} \mathrm{C}$ for thermotolerance assays. One ml culture samples were respectively taken at $0,1,2$ and $3 \mathrm{~h}$ and then their serial dilutions were plated in triplicate. Cell viability was evaluated by counting average colony-forming units from triplicate plates. For salt stress treatment, aliquots from IPTG-induced cultures were treated with $800 \mathrm{mM} \mathrm{NaCl}$ for 1,2 or $3 \mathrm{~h}$, and then were plated on LB medium. For both heat and salt treatments, E. coli cells transformed with empty pET32a $(+)$ vector (Novagen, Merck, Darmstadt, Germany) were used as the control. The photographs of colony formation were taken with after culture on plates for $12 \mathrm{~h}$ at $37^{\circ} \mathrm{C}$.

Constitutive expression of OsHSP20 in yeast. Pichia pastoris SMD1168 strain was used for constitutive expression of OsHSP20 in yeast as described elsewhere ${ }^{44}$. Fragments of the full-length OsHSP20 and its truncated mutants were digested from the recombinant constructs described above (pET32a-OsHSP20 $0^{\text {Full, }}--\mathrm{OsHSP} 20^{\mathrm{N}}$, $-\mathrm{OsHSP} 20^{\mathrm{ACD}}$, -OsHSP20 $0^{\mathrm{C}}$, -OsHSP20 $0^{\mathrm{N}+\mathrm{ACD}}$ and $-\mathrm{OsHSP} 20^{\mathrm{ACD}+\mathrm{C}}$ ) via the BamHI/NotI sites. These fragments were then introduced into the eukaryotic expression vector pPIC3.5 K (Invitrogen, Carisbad, California, USA) as pPIC3.5K-OsHSP2 $20^{\text {Full }}$, -OsHSP20 $20^{\mathrm{N}}$, -OsHSP2 $20^{\mathrm{ACD}},-\mathrm{OsHSP} 20^{\mathrm{C}}$, -OsHSP $20^{\mathrm{N}+\mathrm{ACD}}$ and $-\mathrm{OsHSP} 20^{\mathrm{ACD}+\mathrm{C}}$, respectively. After being linearized with SalI (Thermo Scientific, Waltham, USA), the recombinant vectors and the empty vector pPIC3.5 K were respectively introduced into the SMD1168 cells with MicroPulser ${ }^{\mathrm{TM}}$ electroporator (Bio-Rad, Hercules, CA, USA) and integrated into the genome of SMD1168 cells by homologous recombination. Positive colonies were screened on plates containing yeast extract peptone dextrose (YEPD) medium supplemented with G418 at a concentration of $200 \mathrm{mg} / \mathrm{L}$ for $2-3 \mathrm{~d}$ of incubation at $30^{\circ} \mathrm{C}$ and verified by genomic DNA PCR with the universal primers $5^{\prime}$ AOX1 (5'-GACTGGTTCCAATTGACAAGC-3')/3'AOX1 (5'-GCAAATGGCATTCTGACATCC-3'). SMD1168 cells transformed with empty pPIC3.5 K vector were used as the negative control.

SMD1 168 cells were pre-cultivated in buffered glycerol complex medium (BMGY) and inoculated in buffered methanol complex medium (BMMY) as described in commercial manual. When cultivated aerobically to $\mathrm{OD}_{600}$ of 1.5 , the cultures were used for heat shock treatment at $50^{\circ} \mathrm{C}$ for $1 \mathrm{~h}$. At the end of the first hour, $1 \mathrm{ml}$ of culture samples was collected and diluted into a series of 10 -fold gradient concentration. Aliquots out of these dilutions were spread in triplicate onto YEPD medium plates for estimating their thermotolerance. For salt treatment, aliquots from the cultures $\left(\mathrm{OD}_{600}=1.5\right)$ and dilutions were spread in triplicate on YEPD medium containing $1.2 \mathrm{M} \mathrm{NaCl}$. After incubated in YEPD medium at $30^{\circ} \mathrm{C}$ for $2-3 \mathrm{~d}$, survived cells on plates were photographed and evaluated by calculating the colony formation.

Construction of the plant expression vector and generation of transgenic rice plants. For stable transformation, the encoding region of OsHSP20 was amplified by PCR with the primer pair Trs20-F/ Trs20-R (Supplementary Table 1) and then cloned into the pCAMBIA1300 vector ${ }^{74}$ (Sequence Accession Number: AF234296) to produce p1300-OsHSP20. Subsequently, the recombinant vector was transformed into Agrobacterium tumefaciens strain EHA105. Rice (cv. Nipponbare) transformation was mediated by agrobacterium as previously described ${ }^{75}$. Briefly, the de-husked seeds were sterilized and cultured on NB medium for callus induction at $26^{\circ} \mathrm{C}$ in darkness. The actively growing calli were selected for Agrobacterium-mediated transformation. Regenerated transgenic seedlings were transplanted into soil and allowed to grow till maturity inside a greenhouse. To identify the transgenic rice plants, genomic PCR was performed comparing wild type (WT) and transgenic lines with the universal primers p1300-F $\left(5^{\prime}\right.$-TGGCATATGCAGCAGCTATATGTG- $\left.3^{\prime}\right) /$ p1300-R (5'-ACTCAGTAGGATTCTG GTGTGTGC-3'). In this study, the T2 generations were further analyzed by qRT-PCR and western blotting before being used in subsequent experiments.

Analysis of transgenic rice plants under stress conditions. Seeds of three independent transgenic lines (Ubi:OsHSP20-L5, -L16 and -L20) and wild type (WT) were surface sterilized and plated on 1/2 MS medium for stress assays. For heat stress, the plates were treated at $50^{\circ} \mathrm{C}$ for $12 \mathrm{~h}$ and then transferred to $25^{\circ} \mathrm{C}$ for $10 \mathrm{~d}$. For salt stress, the seeds were shifted to $1 / 2 \mathrm{MS}$ medium with $100 \mathrm{mM} \mathrm{NaCl}$ for $14 \mathrm{~d}$ after germinated on $1 / 2 \mathrm{MS}$ medium for $3 \mathrm{~d}$. The germination percentages were scored and the lengths of the roots were measured for estimating the stress tolerances. The chlorophyll contents of leaves were measured with a chlorophyll meter SPAD-502 (Konica-Minolta, Japan) and recorded as SPAD values. All experiments were done at least three repeats and the data for each repeat were measured from more than 30 seeds or seedlings. 
Received: 19 August 2019; Accepted: 13 January 2020;

Published online: 28 January 2020

\section{References}

1. Ahuja, I., Vos, R. C. H. D., Bones, A. M. \& Hall, R. D. Plant molecular stress responses face climate change. Trends in Plant Science 15, 664-674 (2010).

2. Timperio, A. M., Egidi, M. G. \& Zolla, L. Proteomics applied on plant abiotic stresses: role of heat shock proteins (HSP). Journal of Proteomics 71, 391-411 (2009).

3. Wang, W., Vinocur, B., Shoseyov, O. \& Altman, A. Role of plant heat-shock proteins and molecular chaperones in the abiotic stress response. Trends in Plant Science 9, 244-252 (2004).

4. Garofalo, C. G., Garavaglia, B. S., Dunger, G. G. N., Orellano, E. G. \& Ottado, J. Expression analysis of small heat shock proteins during compatible and incompatible plant-pathogen interactions. Cartography 10, 197-205 (2009).

5. Maimbo, M., Ohnishi, K., Hikichi, Y., Yoshioka, H. \& Kiba, A. Induction of a small heat shock protein and its functional roles in Nicotiana plants in the defense response against Ralstonia solanacearum. Plant Physiology 145, 1588-1599 (2007).

6. Mayer, M. P. Recruitment of HSP70 chaperones: a crucial part of viral survival strategies. Reviews of Physiology, Biochemistry and Pharmacology 153, 1-46 (2005).

7. Mayer, M. P. \& Bukau, B. HSP70 chaperone systems: diversity of cellular functions and mechanism of action. Biological Chemistry 379, 261-268 (1998).

8. Sarkar, N. K., Kim, Y. K. \& Grover, A. Rice sHSP genes: genomic organization and expression profiling under stress and development. BMC Genomics 10, 393-410 (2009).

9. Waters, E. R. The evolution, function, structure, and expression of the plant sHSPs. Journal of Experimental Botany 64, 391-403 (2013).

10. Vierling, E., Harris, L. M. \& Chen, Q. The major low molecular weight heat shock protein in chloroplasts shows antigenic conservation among diverse higher plant species. Molecular \& Cellular Biology 9, 461-468 (1989).

11. Vierling, E. The roles of heat shock proteins in plants. Annu.rev.plant Physiol.plant Mol.biol 42, 579-620 (2003).

12. Santhanagopalan, I. et al. It takes a dimer to tango: oligomeric small heat-shock proteins dissociate to capture substrate. Journal of Biological Chemistry 293, 19511-19521 (2018).

13. Ma, C., Haslbeck, M., Babujee, L. \& Reumann, J. S. Identification and characterization of a stress-inducible and a constitutive small heat-shock protein targeted to the matrix of plant peroxisomes. Plant Physiology 141, 47-60 (2006).

14. Waters, E. R. \& Sanders-Reed, A. Z. Comparative analysis of the small heat shock proteins in three angiosperm genomes identifies new subfamilies and reveals diverse evolutionary patterns. Cell Stress \& Chaperones 13, 127-142 (2008).

15. Siddique, M., Gernhard, S., Koskull-Döring, P. V., Vierling, E. \& Scharf, K. D. The plant sHSP superfamily: five new members inarabidopsis thalianawith unexpected properties. Cell Stress \& Chaperones 13, 183-197 (2008).

16. Mogk, A., Ruger-Herreros, C. \& Bukau, B. Cellular Functions and Mechanisms of Action of Small Heat Shock Proteins. The Annual Review of Microbiology 73, 4.1-4.22 (2019).

17. Haslbeck, M., Weinkauf, S. \& Buchner, J. Small heat shock proteins: simplicity meets complexity. Journal of Biological Chemistry 294, 2121-2132 (2019).

18. Kim, K. K., Kim, R. \& Kim, S. H. Crystal structure of a small heat-shock protein. Nature 394, 595-599 (1998).

19. Montfort, R. L. M. V., Basha, E., Friedrich, K. L., Slingsby, C. \& Vierling, E. Crystal structure and assembly of a eukaryotic small heat shock protein. Nature Structural Biology 8, 1025-1030 (2002).

20. Basha, E., O’Neill, H. \& Vierling, E. Small heat shock proteins and $\alpha$-crystallins: dynamic proteins with flexible functions. Trends in Biochemical Sciences 37, 106-117 (2012).

21. Kirschner, M., Winkelhaus, S., Thierfelder, J. M. \& Nover, L. Transient expression and heat-stress-induced co-aggregation of endogenous and heterologous small heat-stress proteins in tobacco protoplasts. The Plant Journal 24, 397-411 (2000).

22. Giese, K. C. \& Vierling, E. Mutants in a small heat shock protein that affect the oligomeric state: analysis and allele-specific suppression. Journal of Biological Chemistry 279, 32674-32683 (2004).

23. Basha, E., Friedrich, K. L. \& Vierling, E. The n-terminal arm of small heat shock proteins is important for both chaperone activity and substrate specificity. Journal of Biological Chemistry 281, 39943-39952 (2006).

24. Jaya, N., Garcia, V. \& Vierling, E. Substrate binding site flexibility of the small heat shock protein molecular chaperones. Proceedings of the National Academy of Sciences of the United States of America 106, 15604-15609 (2009).

25. Hu, W. H., Hu, G. H. \& Han, B. Genome-wide survey and expression profiling of heat shock proteins and heat shock factors revealed overlapped and stress specific response under abiotic stresses in rice. Plant Science 176, 583-590 (2009).

26. Dietrich, P. S., Bouchard, R. A., Casey, E. S. \& Sinibaldi, R. M. Isolation and characterization of a small heat shock protein gene from maize. Plant Physiology 96, 1268-1276 (1991).

27. Hilton, G. R., Lioe, H. H., Stengel, F., Baldwin, A. J. \& Benesch, J. L. P. Small heat-shock proteins: paramedics of the cell. Topics in current chemistry 328, 69-98 (2012).

28. Lui, J. \& Shono, M. Characterization of mitochondria-located small heat shock protein from tomato (lycopersicon esculentum). Plant and Cell Physiology 40, 1297-1304 (1999).

29. Malik, M. K., Slovin, J. P., Hwang, C. H. \& Zimmerman, J. L. Modified expression of a carrot small heat shock protein gene, HSP17.7, results in increased or decreased thermotolerance. The Plant Journal 20, 89-99 (1999).

30. Lopez-Matas, M. A. et al. Protein cryoprotective activity of a cytosolic small heat shock protein that accumulates constitutively in chestnut stems and is up-regulated by low and high temperatures. Plant Physiology 134, 1708-1717 (2004).

31. Charng, Y. Y., Liu, H. C., Liu, N. Y. \& Ko, H. S. S. Arabidopsis hsa32, a novel heat shock protein, is essential for acquired thermotolerance during long recovery after acclimation. Plant Physiology 140, 1297-1305 (2006).

32. Hamilton, E. W. \& Heckathorn, S. A. Mitochondrial adaptations to nacl. complex $i$ is protected by anti-oxidants and small heat shock proteins, whereas complex ii is protected by proline and betaine. Plant Physiology 126, 1266-1274 (2001).

33. Sato, Y. \& Yokoya, S. Enhanced tolerance to drought stress in transgenic rice plants overexpressing a small heat-shock protein, sHSP17.7. Plant Cell Reports 27, 329-334 (2008).

34. Sun, W., Catherine, B., Cotte, B. V. D., Montagu, M. V. \& Verbruggen, N. At-HSP17.6a, encoding a small heat-shock protein in arabidopsis, can enhance osmotolerance upon overexpression. The Plant Journal 27, 407-415 (2001).

35. Sun, X. et al. AsHSP17, a creeping bentgrass small heat shock protein modulates plant photosynthesis and aba-dependent and independent signalling to attenuate plant response to abiotic stress. Plant, Cell \& Environment 39, 1320-1337 (2016).

36. Lee, B. H. et al. Expression of the chloroplast-localized small heat shock protein by oxidative stress in rice. Gene 245, 283-290 (2000).

37. Neta-Sharir, I., Isaacson, T., Lurie, S. \& Weiss, D. Dual role for tomato heat shock protein 21: protecting photosystem II from oxidative stress and promoting color changes during fruit maturation. The Plant Cell 17, 1829-1838 (2005).

38. Lee, S. H. et al. Identification and functional characterization of siberian wild rye (Elymus sibiricus L.) small heat shock protein 16.9 gene (EsHSP16.9) conferring diverse stress tolerance in prokaryotic cells. Biotechnology Letters 37, 881-890 (2015).

39. Volkov, R. A., Panchuk, I. I., Mullineaux, P. M. \& Schoffl, F. Heat stress-induced h2o2is required for effective expression of heat shock genes inarabidopsis. Plant Molecular Biology 61, 733-746 (2006). 
40. Ramakrishna, W., Deng, Z., Ding, C. K. \& Ozminkowski, H. R. H. A novel small heat shock protein gene, vis1, contributes to pectin depolymerization and juice viscosity in tomato fruit. Plant Physiology 131, 725-735 (2003).

41. Kotak, S., Vierling, E., Baumlein, H. \& von, Koskull-Doring, P. A novel transcriptional cascade regulating expression of heat stress proteins during seed development of Arabidopsis. The Plant Cell 19, 182-195 (2007).

42. Yeh, C. H. et al. Expression of a gene encoding a 16.9-kDa heat-shock protein, OsHSP16.9, in Escherichia coli enhances thermotolerance. Proceedings of the National Academy of Sciences of the United States of America 94, 10967-10972 (1997).

43. Soto, A. et al. Heterologous expression of a plant small heat-shock protein enhances escherichia coli viability under heat and cold stress. Plant Physiology 120, 521-528 (1999).

44. Jiang, C., Xu, J., Zhang, H., Zhang, X. \& Ming, F. A cytosolic class I small heat shock protein, rcHSP17.8, of rosa chinensis confers resistance to a variety of stresses to escherichia coli, yeast and arabidopsis thaliana. Plant Cell and Environment 32, 1046-1059 (2009).

45. Sun, L. et al. ZmHSP16.9, a cytosolic class i small heat shock protein in maize (zea mays), confers heat tolerance in transgenic tobacco. Plant Cell Reports 31, 1473-1484 (2012).

46. Harndahl, U. et al. The chloroplast small heat shock protein undergoes oxidation-dependent conformational changes and may protect plants from oxidative stress. Cell Stress and Chaperones 4, 129-138 (1999).

47. Li, J. B. et al. The populus trichocarpa PtHSP17.8 involved in heat and salt stress tolerances. Plant Cell Reports 35, 1587-1599 (2016).

48. Huang, L. J. et al. CaHSP16.4, a small heat shock protein gene in pepper, is involved in heat and drought tolerance. Protoplasma 256, 39-51 (2019).

49. Li, J., Xiang, C. Y., Yang, J., Chen, J. P. \& Zhang, H. M. Interaction of HSP20 with a viral RdRp changes its sub-cellular localization and distribution pattern in plants. Scientific Reports 5, 14016 (2015).

50. Gao, C. Q., Jiang, B., Wang, Y. C., Liu, G. F. \& Yang, C. P. Overexpression of a heat shock protein (ThHSP18.3) from Tamarix hispida confers stress tolerance to yeast. Molecular Biology Reports 39, 4889-4897 (2012).

51. Mu, C. J. et al. Small heat shock protein LimHSP16.45 protects pollen mother cells and tapetal cells against extreme temperatures during late zygotene to pachytene stages of meiotic prophase I in David Lily. Plant Cell Reports 30, 1981-1989 (2011).

52. Chen, X. \& Zhang, Y. Identification of multiple small heat-shock protein genes in Plutella xylostella (L.) and their expression profiles in response to abiotic stresses. Cell Stress and Chaperones 20, 23-35 (2015).

53. Muthusamy, S. K., Dalal, M., Chinnusamy, V. \& Bansal, K. C. Genome-wide identification and analysis of biotic and abiotic stress regulation of small heat shock protein (HSP20) family genes in bread wheat. Journal of Plant Physiology 211, 100-113 (2017).

54. Fujita, Y., Fujita, M., Shinozaki, K. \& Yamaguchi-Shinozaki, K. ABA-mediated transcriptional regulation in response to osmotic stress in plants. Journal of Plant Research 124, 509-525 (2011).

55. Yang, X. Q. et al. Characterization of multiple heat-shock protein transcripts from Cydia pomonella: their response to extreme temperature and insecticide exposure. Journal of Agricultural and Food Chemistry 64, 4288-4298 (2016).

56. Lee, K. W. et al. Overexpression of alfalfa mitochondrial HSP23 in prokaryotic and eukaryotic model systems confers enhanced tolerance to salinity and arsenic stress. Biotechnology Letters 34, 167-174 (2012).

57. Tilly, K., McKittrick, N., Zylicz, M. \& Georgopoulos, C. The dnaK protein modulates the heat-shock response of Escherichia coli. Cell 34, 641-646 (1983)

58. Praekelt, U. M. \& Meacock, P. A. HSP12, a new small heat shock gene of Saccharomyces cerevisiae: analysis of structure, regulation and function. Molecular and General Genetics 223, 97-106 (1990).

59. Chauhan, H., Khurana, N., Nijhavan, A., Khurana, J. P. \& Khurana, P. The wheat chloroplastic small heat shock protein (sHSP26) is involved in seed maturation and germination and imparts tolerance to heat stress. Plant Cell \& Environment 35, 1912-1931 (2012).

60. Zhao, C. et al. Constitutive expression of an endoplasmic reticulum small heat shock protein alleviates endoplasmic reticulum stress in transgenic tomato. Journal of Plant Physiology 164, 835-841 (2007).

61. Zhang, L. et al. Overexpression of heat shock protein gene PfHSP21.4 in Arabidopsis thaliana enhances heat tolerance. Acta Physiologiae Plantarum 36, 1555-1564 (2014).

62. Wang, A. et al. Overexpression of a small heat-shock-protein gene enhances tolerance to abiotic stresses in rice. Plant Breeding 134, 384-393 (2015).

63. Volkov, R. A., Panchuk, I. I. \& Schoffl, F. Small heat shock proteins are differentially regulated during pollen development and following heat stress in tobacco. Plant Molecular Biology 57, 487-502 (2005).

64. Kaur, H. et al. Differentially expressed seed aging responsive heat shock protein OsHSP18.2 implicates in seed vigor, longevity and improves germination and seedling establishment under abiotic stress. Frontiers in Plant Science 6, 713 (2015).

65. Wahid, A., Gelani, S., Ashraf, M. \& Foolad, M. R. Heat tolerance in plants: An overview. Environmental and Experimental Botany 61, 199-223 (2007)

66. Wang, M. L. et al. The CsHSP17.2 molecular chaperone is essential for thermotolerance in Camellia sinensis. Scientific Reports 7, 1237 (2017).

67. Cha, J. Y. et al. N-terminal arm of orchardgrass HSP17.2 (OgHSP17.2) is essential for both in vitro chaperone activity and in vivo thermotolerance in yeast. Archives of Biochemistry and Biophysics 591, 18-27 (2016).

68. Schmittgen, T. D. \& Livak, K. J. Analyzing real-time PCR data by the comparative C(T) method. Nature Protocols 3, 1101-1108 (2008).

69. Gietz, R. D. \& Woods, R. A. Transformation of yeast by lithium acetate/single-stranded carrier DNA/polyethylene glycol method. Methods in Enzymology 350, 87-96 (2002).

70. Laemmli, U. K. Cleavage of structural proteins during the assembly of the head of bacteriophage T4. Nature 227, 680-685 (1970).

71. Bradford, M. M. A rapid and sensitive method for the quantification of microgram quantities of protein utilizing the principle of protein-dye binding. Analytical Biochemistry 72, 248-254 (1976).

72. He, J., Liu, H., Guo, L. M., Li, J. \& Zhang, H. M. Characterization and application of antibodies against a small heat shock protein (OsSHSP) from Oryza sativa. Chinese Journal of Rice Science 33, 235-240 (2019).

73. Basha, E., Lee, G. J., Demeler, B. \& Vierling, E. Chaperone activity of cytosolic small heat shock proteins from wheat. European Journal of Biochemistry 271, 1426-1436 (2004).

74. Hajdukiewicz, P., Svab, Z. \& Maliga, P. The small, versatile pPZP family of Agrobacterium binary vectors for plant transformation. Plant Molecular Biology 25, 989-994 (1994).

75. Hiei, Y., Ohta, S., Komari, T. \& Kumashiro, T. Efficient transformation of rice (Oryza sativa L.) mediated by Agrobacterium and sequence analysis of the boundaries of the T-DNA. The Plant Journal 6, 271-282 (2010).

\section{Acknowledgements}

This work was funded by the National Natural Science Foundation of China (31601603 and 31972980), the Key Research and Development Program of Zhejiang Province (2019C02018), and the National Key Research and Development Plan in China (2016YFD0200800). We thank Prof. M. J. Adams, Minehead, UK for help in correcting the English of the manuscript. 


\section{Author contributions}

H.Z. were responsible for study conception, design, and coordination; L.G., J.L., J.H. and H.L. carried out the experiments for vector construction in E. coli and yeast cells, heterologous expression, SDS-PAGE, Western Blotting, and molecular chaperone activity assays; J.L. and L.G. and designed primers and optimized the conditions for quantitative assays; L.G., J.H. and H.L. performed abiotic treatments, and sample collection, RNA isolation, and Real time RT-PCR; L.G., J.L. and J.H. carried out the binary vector construction, generation of transgenic plants, interest gene expression assays, and measure of germination rate and root length. H.Z. and J.L. were responsible for data collection and analysis and drafted the manuscript. All authors read and approved the final manuscript.

\section{Competing interests}

The authors declare no competing interests.

\section{Additional information}

Supplementary information is available for this paper at https://doi.org/10.1038/s41598-020-58395-8.

Correspondence and requests for materials should be addressed to H.-M.Z.

Reprints and permissions information is available at www.nature.com/reprints.

Publisher's note Springer Nature remains neutral with regard to jurisdictional claims in published maps and institutional affiliations.

(c) (i) Open Access This article is licensed under a Creative Commons Attribution 4.0 International License, which permits use, sharing, adaptation, distribution and reproduction in any medium or format, as long as you give appropriate credit to the original author(s) and the source, provide a link to the Creative Commons license, and indicate if changes were made. The images or other third party material in this article are included in the article's Creative Commons license, unless indicated otherwise in a credit line to the material. If material is not included in the article's Creative Commons license and your intended use is not permitted by statutory regulation or exceeds the permitted use, you will need to obtain permission directly from the copyright holder. To view a copy of this license, visit http://creativecommons.org/licenses/by/4.0/.

(C) The Author(s) 2020 